\title{
DO PLANEJAMENTO TRADICIONAL DE TRANSPORTE AO MODERNO PLANO INTEGRADO DE TRANSPORTES URBANOS
}

\author{
Claudio de Senna Frederico \\ Secretário dos Transportes Metropolitanos do Governo do Estado de São Paulo
}

\begin{abstract}
Resumo: Reflexões sobre os planos de transporte elaborados para a cidade e a Região Metropolitana de São Paulo; a peculiaridade dos planos tradicionais de transportes; análise crítica dos planos e das implantações de linhas metroviárias; a inserção da ferrovia na malha de trilhos da região; análise dos planos e das ações em transporte urbano no Governo Mário Covas; o Pitu 2020 e seu diferencial na história dos planos de transporte; as formas antigas e novas de financiamento do transporte público.

Palavras-chave: plano de transporte; metrô; trem; ônibus; metropolitano; financiamento público.
\end{abstract}

$\mathrm{E}$ m dezembro de 1968, foram publicados, pelo governo do prefeito Faria Lima, os resultados finais do estudo econômico-financeiro e pré-projeto de engenharia da rede de metrô para São Paulo (Prefeitura do Município de São Paulo, 1968). Já nas primeiras páginas, quando trata dos objetivos do trabalho, há a declaração de ser um estudo "baseado na análise da situação atual dos transportes urbanos na cidade de São Paulo e na prognose de seu desenvolvimento", definição sucinta do que foi e ainda é o planejamento tradicional de transporte. Ou seja, o presente e suas demandas foram as bases para as projeções. Não vai, nessa afirmação, nenhuma crítica a um trabalho pioneiro à época que utilizou técnicas avançadas - como a apropriação dos dados da pesquisa Origem-Destino e sua modelagem matemática para projeções - que, até hoje, ainda não são usadas consistentemente na maioria das cidades do mundo. Mas, de fato, o plano tratou de enxertar um novo modo de transporte o metrô - a uma malha preexistente de viagens, sem estabelecer uma solução completa e sem procurar modelar, inicialmente, uma cidade e, dentro dela, o tipo de vida de seus habitantes.

A concepção tradicional dirige o olhar para aceitar (percepção ainda presente hoje) a situação de deslocamentos levantada e prevista como fatos naturais, escolher determinado modal como solução e correr atrás do prejuízo. E isso em uma cidade reconhecidamente carente de infra- estrutura, inclusive para transportes, com crescimento populacional vertiginoso, conseqüência de volumosas migrações populacionais.

Até que a visão integrada existe nesse plano. Os eixos principais das linhas de metrô procuram ao máximo interceptar as linhas ferroviárias existentes, mas, no final, é como se aquela ferrovia fosse uma entidade independente e estática, a ser respeitada e considerada, mas não incorporada ao sistema. Por certo, o modal "escolhido" foi o metrô e isso significou o abandono dos demais.

\section{PLANEJAMENTO TRADICIONAL DE TRANSPORTES: CORRENDO ATRÁS DO RABO}

\section{Um Bom Exemplo: a Rede Básica do Metrô de São Paulo}

As condições existentes em 1968 parecem persistir. É curioso observar que o arrazoado inicial preconizando a necessidade do metrô poderia ser repetido até hoje, justificando qualquer intervenção na área de transportes urbanos em São Paulo. Todos os itens estão ainda presentes, exceto um, muito importante: "o crescimento (...) demográfico da cidade superou o da maioria das grandes metrópoles mundiais". Ao contrário, a Região Metropolitana de São Paulo e, em particular, o Município da capital reduziram seu crescimento populacional a níveis muito 
baixos. O crescimento que continua explosivo é o dos veículos, mas, também, tende a se reduzir, uma vez que foram alcançadas taxas de motorização superiores às das grandes metrópoles do Primeiro Mundo. No entanto, novas áreas urbanizadas continuam se incorporando à já imensa mancha urbana, rapidamente, pela nova migração interna de regiões centrais dirigida a invasões e loteamentos clandestinos periféricos.

Essa nova ordem, entranhada de situações anteriores ainda presentes e não-resolvidas e de novas dinâmicas de povoamento, está a exigir outro tipo de planejamento.

\section{Pontos Básicos}

Os pontos principais da única rede básica oficial do Metrô de São Paulo eram resultado do atendimento às carências de transporte identificadas pela pesquisa Origem-Destino de 1967, mais tarde atualizada e a cada dez anos. Somavam-se a isso, as previsões para os primeiros dez anos de alterações na mobilidade e o entendimento de que a extensa malha ferroviária existente na região teria sua capacidade e qualidade recuperadas, além da prioridade dada à ultrapassagem do Rio Tietê em diversos pontos.

$O$ resultado era apresentado como uma malha de quatro linhas e dois ramais totalizando $66 \mathrm{~km}$, com as seguintes características:

- linha Norte-Sul, com 20,98 km, de Jabaquara a Santana, incluindo um ramal de Paraíso a Moema pelo traçado da

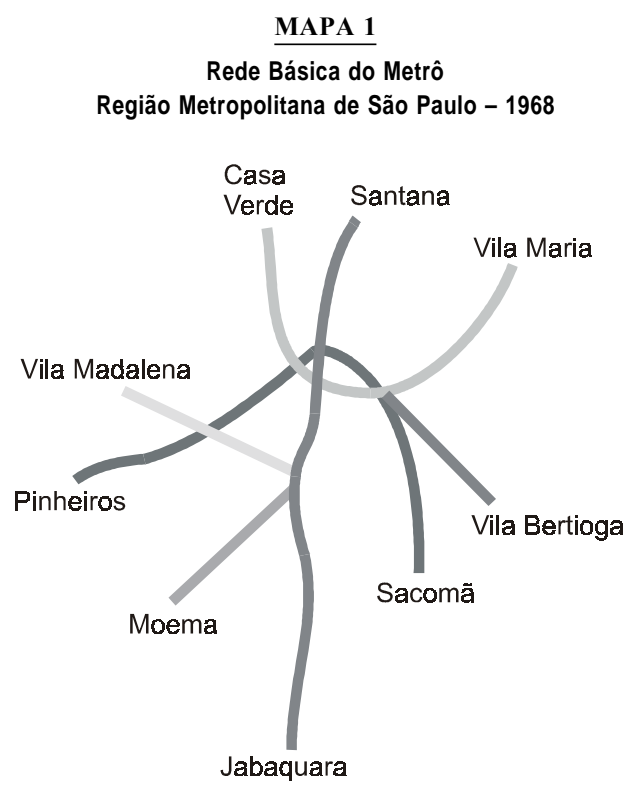

Fonte: Prefeitura do Município de São Paulo, 1968. antiga linha de bondes de Santo Amaro. Esta linha criaria uma passagem ao norte do Rio Tietê e uma integração ferroviária na Luz. Sua construção foi iniciada em 1968 e concluída em 1976, sem o ramal de Moema;

- linha Leste-Oeste, com 13,33 km, em forma de U, iria de Casa Verde a Vila Maria, criando duas passagens ao norte do rio Tietê e uma integração com as ferrovias a oeste em Barra Funda e outra a leste em Brás-Roosevelt;

- linha Sudoeste-Sudeste, com 23,83 km, em forma de U invertido, do Jóquei Clube, em Pinheiros, à estação da Luz e depois até o Sacomã, no início da rodovia Anchieta, com um ramal do Parque D. Pedro II até Vila Bertioga, logo após o Alto da Mooca. Esta linha criaria uma passagem sobre o rio Pinheiros e uma integração ferroviária na Luz; - linha Paulista, com 8,08 km, de Vila Madalena ao Paraíso, apenas integrando outras linhas da rede.

\section{Desvios e Diferenças}

As principais diferenças entre a rede básica planejada e a executada foram:

- abandono da idéia inicial de ramais pelas dificuldades de operação e pela previsível saturação das linhas mesmo sem os ramais, exemplificado pela não-construção do ramal de Moema na linha Norte-Sul;

- desistência de dar prioridade às passagens sobre o Rio Tietê em benefício de atender ao crescimento urbano a leste. Nessa decisão está incluída, ainda, a desistência da espera por melhoria do sistema ferroviário. O maior exemplo foi a linha Leste-Oeste que passou a iniciar-se, a oeste, na Barra Funda e não na Casa Verde e, a leste, estendeu-se até Itaquera, em vez de terminar em Vila Maria. Esta linha passou a ser o "calcanhar de Aquiles" do Metrô, com seu imediato saturamento em uma operação de características pendulares de carregamento, com picos muito acentuados, mais similar a uma linha de trem de subúrbio a que, de fato, estava substituindo;

- a linha Paulista, prevista para ser a última, começou a ser construída em segundo lugar, tendo sido interrompida e depois reiniciada, com a intenção de continuar depois de Paraíso e Ana Rosa na direção de Ipiranga e Vila Prudente, substituindo parte do ramal D. Pedro-Vila Bertioga, abandonado;

- principalmente por motivos político-eleitoreiros, surgiram as extensões de linhas existentes, mais fáceis e rápidas de ser construídas: da linha Norte-Sul, de Santana ao 
Tucuruvi, e da Leste-Oeste, de Itaquera a Guaianases. Apesar de sua aparente facilidade, as extensões foram iniciadas no início dos anos 90 , tiveram suas obras interrompidas e só foram concluídas no final da década, neste governo.

\section{Faltaram Sucessores}

Um dos grandes méritos do estudo citado - que passou a ser conhecido pela corporação dos transportes como "O livrão", ou "O livro azul" - foi deixar claro um objetivo do plano: estabelecer quatro linhas e dois ramais do metrô, num total de $66 \mathrm{~km}$. A clareza do que se pretendia fez com que, após o início da construção da linha Norte-Sul, os potenciais beneficiários e os estudiosos do assunto passassem a cobrar novas linhas com o traçado conhecido, como estava no plano. Esse conjunto, denominado rede básica do metrô, passou a ser um ente político e uma fita métrica para medir a eficiência ou não das administrações municipais que se sucederam.

Infelizmente, a rede nunca foi implantada em sua totalidade e, mesmo a segunda linha completada (a LesteOeste, hoje chamada linha 3 - Vermelha), já não tinha muito a ver com seu projeto original. Independentemente de acerto ou erro da decisão sobre a seqüência de linhas a construir, nunca mais foi publicado um plano tão compreensivo quanto o original, que apresentasse claramente à "torcida" por que linhas ela deveria "torcer". Faltaram planos sucessores.

\section{Usando e Abusando: Utilidade, Mentiras e Manipulação}

A ausência de planos sucessores oficiais, com a abrangência do plano do prefeito Faria Lima, fez com que quaisquer estudos, principalmente os gerados pela própria Companhia do Metrô de São Paulo, fossem - e sejam ainda utilizados para medir o que falta. $O$ foco é sempre o que falta, esquecendo-se, os planejadores e interessados, das conquistas reais que esse sistema de transporte representou não só para São Paulo, mas para o transporte público e, mesmo, para o serviço público no Brasil.

Até hoje, são comuns falas sobre redes de $150,180 \mathrm{e}$ até $400 \mathrm{~km}$ de metrô como indispensáveis à cidade. $\mathrm{O}$ número de $400 \mathrm{~km}$ aparece em comparação com cidades como Paris, apesar de não representar a realidade daquela cidade onde o metrô, além disso, é resultado de 100 anos de implantação. O número em torno de $180 \mathrm{~km}$ é oriundo, geralmente, da comparação com a Cidade do México que iniciou a construção de seu sistema poucos anos antes de São Paulo. Mas, os que comparam não lembram que o sistema de transporte público daquela cidade é pior que o da capital paulista, o trânsito é caótico e a situação de poluição, muito pior.

A pior manipulação das informações parece ser a atribuição exclusiva ao Estado da responsabilidade por investir na rede de metrô. No entanto, até 1994, o projeto de linhas de metrô obedecia exclusivamente a uma lógica de atendimento da demanda municipal, com tímidas integrações tarifárias com linhas de ônibus do município. Os traçados das linhas de metrô pareciam "evitar" sair dos limites municipais. Os preconizadores da responsabilidade do Estado parecem se esquecer de que, desde a Constituição de 1988, a responsabilidade pelo transporte público é atribuição municipal. Parece ter-se estabelecido, entre nós, uma divisão de responsabilidades por modal e não pelas viagens. Enquanto o ônibus pode ser utilizado por todas as esferas de governo para cumprir suas obrigações, somente o Estado pode e tem de expandir a rede de metrô.

\section{O PROGRAMA INTEGRADO}

Ao assumir o governo de São Paulo, em 1995, o governador Mário Covas instituiu o Programa Integrado de Transportes Urbanos - Pitu. Esse é um programa um pouco mais avançado no planejamento tradicional, pois não é resultado, simplesmente, de uma avaliação da situação presente e prognose. Duas idéias-força estão presentes no programa de ação do governo e são a base para sua formulação, a partir de 1995: a integração dos transportes que existiam, de responsabilidade do Estado, e a busca de formas novas de financiamento dos investimentos que fossem sugeridos.

A integração estudada significou, a princípio, a complementação de gestão do transporte metropolitano, centralizada sob a mesma autoridade: a Secretaria dos Transportes Metropolitanos - STM. Dessa maneira, o planejamento, a administração, fiscalização e operação de todos os modais de transporte metropolitano passaram a ser exercidos pela STM, diretamente ou por meio das empresas vinculadas (Cia. Paulista de Trens Metropolitanos - CPTM, Cia. do Metropolitano de São Paulo - Metrô e Empresa Metropolitana de Transportes Urbanos EMTU). A esse conjunto, vieram se agregar as funções de execução, organização e coordenação das políticas para 
as regiões metropolitanas no Estado de São Paulo, uma vez que a Secretaria abrigou, em sua estrutura, o Fundo Metropolitano de Financiamento e Investimento - Fumefi e a Empresa Metropolitana de Planejamento da Grande São Paulo - Emplasa. Portanto, as condições para a execução de um programa integrado estavam dadas.

O conjunto de projetos em obras ou já finalizados - a maioria já nessa última condição - do Pitu envolve a inclusão do poder público em:

- empreendimentos de infra-estrutura, basicamente constituídos pelas conclusões de diversas obras paralisadas, envolvendo linhas de metrô, corredores e centros de controle;

- recuperação das ferrovias e sua transformação em novos serviços de metrô, que abrangem ainda a integração de linhas ferroviárias e a ampliação da frota de trens;

- expansão do transporte metropolitano de alta e média capacidades, destacando-se as novas linhas de metrô, a concessão e eletrificação de corredores e sua troncalização; - ações de gestão, envolvendo pesquisas, política tarifária, comunicação visual e a efetiva participação do usuário final no controle de qualidade dos serviços prestados;

- processo contínuo de planejamento, resultando no Plano Integrado dos Transportes Urbanos para 2020 - Pitu 2020, um plano para resolver o futuro dos transportes públicos de São Paulo.

\section{A Recuperação das Ferrovias}

Em 1995, no primeiro ano do primeiro mandato do atual governo estadual, as ferrovias tinham acabado de ser unificadas em uma nova empresa estadual, a Companhia Paulista de Trens Metropolitanos - CPTM. Todas as linhas se encontravam defasadas e muitas com material obsoleto e em péssima conservação.

Os serviços, principalmente na parte transferida da CBTU pelo Governo Federal, eram julgados como o pior serviço de transporte público urbano por seus usuários, nas pesquisas realizadas pela Associação Nacional de Trânsito e Transportes Públicos - ANTP. Seus dois grandes sistemas, leste e oeste, nem mesmo permitiam a integração com passagem livre entre eles, como as linhas do Metrô, e não incentivavam a integração com este serviço de melhor qualidade.

Ao longo dos anos vem sendo realizado um programa de melhorias em todas as linhas com investimentos na casa de bilhões de reais que já trouxeram as seguintes:

\section{Novos e Modernos Trens}

Foram adquiridos 30 Trens Unidade Elétrico (TUEs) e modernizados outros 48 , de origem espanhola, todos eles dotados de um sistema de climatização, incluindo peças, componentes e módulos de reposição para manutenção,

MAPA 2

Rede de Metrô

Região Metropolitana de São Paulo - 1995

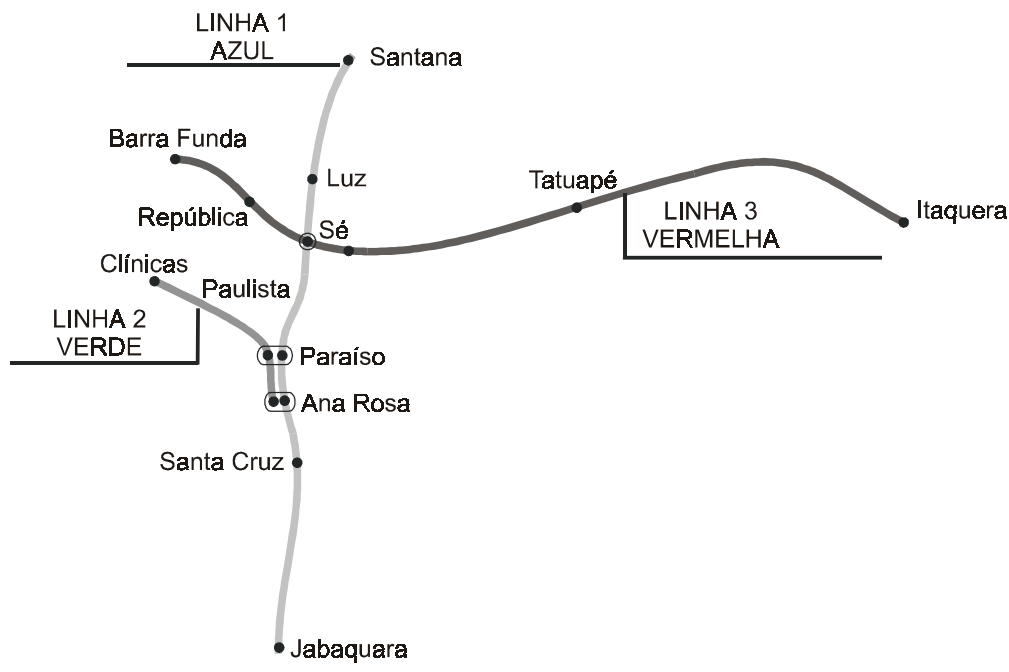

Fonte: Metrô. 
equipamentos de teste e diagnóstico, dispositivos e ferramentas especiais. Esses estão, hoje, circulando no Expresso Leste e na linha $C$, que ladeia a marginal do Rio Pinheiros, e na linha D, de Brás até Guaianases. Outros trens, alemães, vão se juntar aos espanhóis e circularão na linha C da CPTM, futura linha 6 - Celeste do Metrô.

\section{Prioridade à Periferia Leste e Sul}

Desde a pesquisa OD de 1987, as regiões sul (Capão Redondo/Campo Limpo/Grajaú) e leste (Itaquera/Guaianases/Itaquaquecetuba) aparecem como as mais carentes de transporte público de massa. Em benefício dessas regiões foram iniciadas as seguintes obras:

- Projeto Leste: não adiantava apenas estender a linha Leste do Metrô que já se encontrava saturada. Assim, o novo trecho, cujas obras ficaram por muito tempo paradas e foram retomadas e terminadas na atual gestão, foi incorporado à linha ferroviária existente que recebeu várias ações de melhoria. As principais intervenções no trecho foram: três novas estações (Dom Bosco, José Bonifácio e Guaianases); incorporação da estação Corinthians-Itaquera servindo ao metrô e ao trem; estabelecimento de $8 \mathrm{~km}$ de via permanente e rede aérea (extensão Leste) entre as estações Artur Alvim e Guaianases; construção de três terminais de integração em Itaquera, José Bonifácio e Guaianases; desativação das estações Guaianases (antiga), Patriarca, Vila Matilde, Carlos de Campos, Artur Alvim, Itaquera (antiga), XV de Novembro e Sebastião Gualberto; desativação de trecho de via compreendido entre as estações Artur Alvim e Guaianases (antiga); modernização da via permanente e rede aérea no trecho Sebastião Gualberto-Brás; modernização e complementação do sistema de alimentação e radiocomunicações.

Após as obras, um novo serviço foi entregue à população: o Expresso Leste, um serviço expresso do Brás a Guaianases com integração livre entre trem e metrô no Brás. Esse serviço é o embrião da futura linha 6 do Metrô em 2002.

- Dinamização da linha Sul do trem metropolitano: a principal deficiência da antiga linha da Fepasa ao longo do Rio Pinheiros, que vai de Osasco a Jurubatuba, era a falta de estações entre Pinheiros e Santo Amaro, além de sua capacidade e material rodante deficientes. Foi iniciado e está em conclusão o projeto de dinamização dessa linha com a construção de sete novas estações, novos trens, vias, sistema elétrico e sinalização, tornando a linha compatível com uma linha de metrô.
- Linha 5 do Metrô: está em construção, para inauguração em 2002, a primeira linha totalmente nova de metrô em 23 anos, com 9,4 quilômetros de extensão, em seu primeiro trecho, entre Capão Redondo e Largo 13 de Maio em Santo Amaro.

\section{Integração Livre}

O pressuposto da integração ganhou nova dimensão, com a introdução de passagens livres de diversos tipos entre metrô e trem metropolitano, inclusive com a utilização de outros modos de transporte. Nessa direção é que se lê a incorporação do fenômeno de transportes clandestinos por vans ao sistema regular de transporte. Tratouse, não de repelir o novo modo de transporte, aceito e incentivado pelos usuários, mas de utilizá-lo a favor do transporte regular. Foram instituídas, então, as Pontes Orca, sistema de interligação gratuita entre estações de trem e de metrô, operado pelo que se designou Operadores Regulares Coletivos Autônomos - os Orcas. Esse novo serviço foi instaurado entre as estações Barra Funda (que serve ao metrô e ao trem) e Vila Madalena (do metrô) e entre esta e a estação Cidade Universitária (do trem, na marginal do Pinheiros).

Além desse novo modo de integração, outro foi ousadamente estabelecido, a despeito do receio dos partidários do tradicional planejamento de transporte, porque não estava embasado em experiências anteriores ou não havia como fazer prognoses a partir da "situação atual": a passagem livre entre estações de trem e metrô, nas estações Brás e Barra Funda e, mais recentemente, entre as estações Luz da CPTM e Luz do Metrô.

\section{A Integração se Torna Tarifária}

Em 2002, será lançado o Metropass, o smart card dos transportes metropolitanos, possibilitando que as experiências de passagens livres, hoje restritas ao descrito anteriormente, ocorram em todo o sistema. Inicialmente restrito ao transporte, esse sistema pode se ampliar e o mesmo cartão ser utilizado em outros serviços, como pagamento de pedágio, passagens em ônibus intermunicipal, etc. $\mathrm{O}$ Metropass pode gerar, ainda, uma série de promoções no transporte coletivo (como o sistema de milhagem), valorizando esse setor e conferindo status ao seu usuário.

Muitas outras ações desencadeadas pelo Pitu foram e estão sendo adotadas nos transportes metropolitanos, como a reorganização dos sistemas de linhas de ônibus metro- 
politanos, as licitações para as concessões desse transporte nas Regiões Metropolitanas de São Paulo e Baixada Santista, a utilização, pela primeira vez no mundo, de técnicas de pesquisa de opinião para fiscalização direta das concessões, o tratamento padronizado dos chamados caminhos metropolitanos (as vias de uso e interesse de mais de um município nas regiões metropolitanas de São Paulo). Esses temas podem ser retomados em outra ocasião, outro artigo, uma vez que o espaço é limitado e devemos abordar, ainda, o novo modelo de planejamento dos transportes desenvolvido, o Plano Integrado dos Transportes Urbanos para 2020, o Pitu 2020.

\section{O NOVO HERDEIRO: O PITU 2020}

Em 1998, após a realização da nova pesquisa OrigemDestino realizada em 1997 que trouxe dados atualizados sobre os fluxos de deslocamento na Região Metropolitana de São Paulo, começou a fase final do que seria o sucessor moderno do estudo da rede básica de metrô de 1968.

Pela primeira vez, o transporte era planejado em função do seu impacto sobre a metrópole e o tipo de vida desejado por seus habitantes. Também pela primeira vez, partia-se para a elaboração de um plano com a participa- ção das prefeituras da região, principalmente da capital. Em vez de apenas um resultado estático, o plano pretendeu deixar uma metodologia dinâmica, um processo de planejamento retroalimentado, que poderia ser reutilizado quantas vezes fosse desejado para restaurar o mesmo exercício no futuro.

Ao mesmo tempo que a utilidade inicial de "publicar" uma rede definitiva de metrô seria atingida, também as outras providências na área de transporte, em suas esferas estaduais e municipais, estariam contempladas. O resultado final foi apresentado no Mosteiro de São Bento em julho de 2000. O local escolhido para lançamento tem um caráter simbólico em um plano como este: nesse mesmo mosteiro se encontra a primeira construção de alvenaria da cidade e é nesses arredores que está o ponto de partida do aldeamento inicial da metrópole. Dessa forma, simbolizava-se a volta às origens para repensar e domar as forças espontâneas de formação urbana dando-lhes um destino construtivo.

\section{Pitu e Pitu 2020 são a mesma coisa?}

É importante salientar as diferenças do novo instrumento - Pitu 2020 - do que já vinha sendo utilizado pela Se-

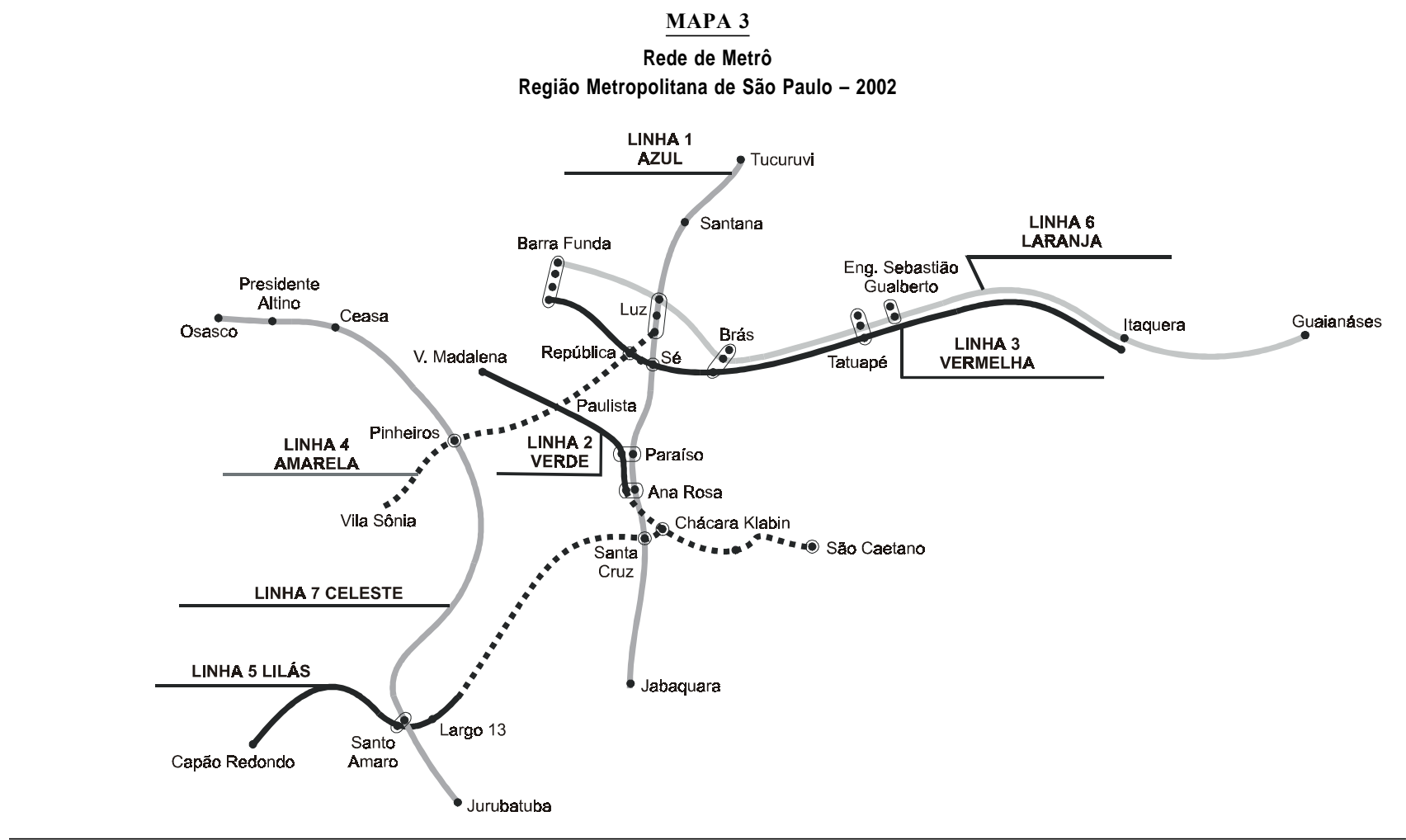

Fonte: Secretaria dos Transportes Metropolitanos (2000). 
cretaria de Transportes Metropolitanos desde 1995, o Pitu. Este continua sendo um programa, instrumento de trabalho e coordenação, que declara o conjunto de ações já deflagradas. Isto significa que um projeto, que deve ser parte do Pitu 2020, já com recursos, obras, contratos em andamento ou em negociação, passa a fazer parte do Pitu com seus objetivos, custos, fontes e responsáveis indicados claramente.

Enquanto isso, o Pitu 2020 é o plano que identifica, para dado momento, a visão de conjunto não só do que está no Pitu (programa) mas daquilo que deve se tornar viável para o início de sua implantação. O Pitu 2020 é um cenário a ser perseguido por todos e apropriado ao mundo real da forma oportunista que for surgindo.

\section{Princípios do Pitu 2020: a cidade que desejamos}

O Pitu 2020 teve um início diferente: em vez de prognósticos frios sobre o futuro, partiu da formulação de um desejo. Uma reflexão sobre como queremos estar vivendo em 2020, qual será a cara de nossa metrópole. O sonho, construído coletivamente por diversos agentes que decidem os rumos da cidade - prefeitos municipais, secretários municipais de transporte, técnicos de empresas operadoras, urbanistas e estudiosos do transporte público-, é estruturar uma metrópole competitiva, saudável, equilibrada, responsável e cidadã. As estratégias específicas para os transportes metropolitanos partem dessa estação.

\section{Metodologia do PITU 2020: participação e flexibilidade}

Mais que um plano, o Pitu 2020 pretende ser um processo: contínuo de planejamento dinâmico, que possa incorporar as mudanças sociais e econômicas; democrático, que envolva os agentes responsáveis pela gestão e operação do transporte; completo, que examine não só os investimentos, mas as medidas de gestão do sistema; realista, que proponha medidas de financiamento regular.

\section{Planejamento Estratégico}

No dicionário, estratégia é a "arte de explorar condições favoráveis com o fim de alcançar objetivos específicos". Por extensão, essa é a definição do planejamento estratégico usado no Pitu 2020. O plano começa com a visão futura da metrópole. A cidade que sonhamos nos diz qual o rumo a seguir. A partir dela, a seqüência é téc- nica: visão futura da metrópole; objetivos da política de transporte; indicadores de desempenho; cenários futuros socioeconômicos e urbanos; estratégias nos cenários futuros; melhor estratégia para a metrópole sonhada; e propostas do Pitu 2020.

\section{Modelagem de Apoio}

Foi usado o simulador Strategic and Regional Model Start, desenvolvido pela MVA Consultancy e adaptado pela Setepla Tecnometal Engenharia Ltda. às condições de São Paulo. O Start tem, como diferencial, o modo como simula com maior riqueza de detalhes o processo de escolha do usuário de transporte. O modelo vai mais longe, calculando os impactos das políticas propostas para o futuro e avaliando os benefícios para todos os segmentos da sociedade.

\section{Resultados do Plano: solução e não melhoria}

Uma das características marcantes do Pitu 2020 é que seu objetivo é a solução e não a melhoria apenas. Solução que, tanto quanto possa ser prevista em determinado momento, uma vez "construída" resultará na obtenção da metrópole utópica que foi imaginada como sua premissa.

É uma pena que no Brasil existam tão poucos planos que identifiquem para uma determinada visão a "solução" de qualquer problema com seus custos e prováveis prazos identificados objetivamente. O Pitu 2020 se propõe como escola para esse exercício político de planejar dinamicamente e em conjunto a realidade futura a ser construída por todos.

\section{Principais Propostas}

Um exercício mostra os prejuízos pela não-execução de um plano de transportes como o preconizado pelo Pitu 2020 e os ganhos com sua aplicação. Caso não seja executado, ou somente sejam finalizados os investimentos já iniciados, a situação da mobilidade urbana na Região Metropolitana de São Paulo seria a seguinte:

- as viagens de automóvel crescem $80 \%$;

- cai de $50 \%$ para $43 \%$ a participação do transporte público nas viagens urbanas;

- cresce o tempo gasto em viagens: $45 \%$ para o transporte público e $60 \%$ para o automóvel;

- a velocidade no centro expandido na hora de pico diminui $25 \%$; 
- aumenta o monóxido de carbono no centro expandido.

Com a implantação do Pitu, esse quadro se reverte e os ganhos seriam:

- a mobilidade recupera as condições existentes em 1977, mesmo com o aumento populacional;

- aumenta para $60 \%$ a participação do transporte público; - aumenta a velocidade média das viagens em 20\% (35\% na velocidade das viagens coletivas, $30 \%$ na velocidade das viagens da população de baixa renda e $16 \%$ no centro expandido);

- reduz-se o monóxido de carbono no centro expandido.

O resultado dessa primeira construção da metrópole desejada será uma metrópole totalmente acessível por transporte público. Serão $284 \mathrm{~km}$ de novas linhas metroviárias, um trem especial ligando os aeroportos, a modernização das linhas ferroviárias "de aproximação" entre a periferia distante e os pólos da metrópole, a reformulação nas ligações ferroviárias regionais da Região Metropolitana de São Paulo com Sorocaba, Campinas e
São José dos Campos, corredores de ônibus, "bondes" modernos, linhas circulares de microônibus no centro expandido, um plano viário metropolitano - os caminhos metropolitanos -, obras de melhorias nas rodovias, o rodoanel, o plano municipal de tráfego e sistema viário do município de São Paulo, melhorias operacionais no viário da capital, estacionamentos centrais (em garagens subterrâneas) e periféricos (próximos ao sistema de trilhos). E, ainda, uma medida polêmica: a proposta, pelo município, do pedágio urbano.

\section{Fontes de Recursos}

O investimento total necessário para instituir, ao longo dos próximos 20 anos, o Pitu 2020, é de R\$ 30,3 milhões. Nesse valor estão inclusos investimentos que já estão sendo feitos pelo governo do Estado e investimentos programados pelos municípios, como as melhorias viárias propostas pela Prefeitura de São Paulo na ocasião da elaboração do Pitu 2020. Hoje, com novos prefeitos, os mu-

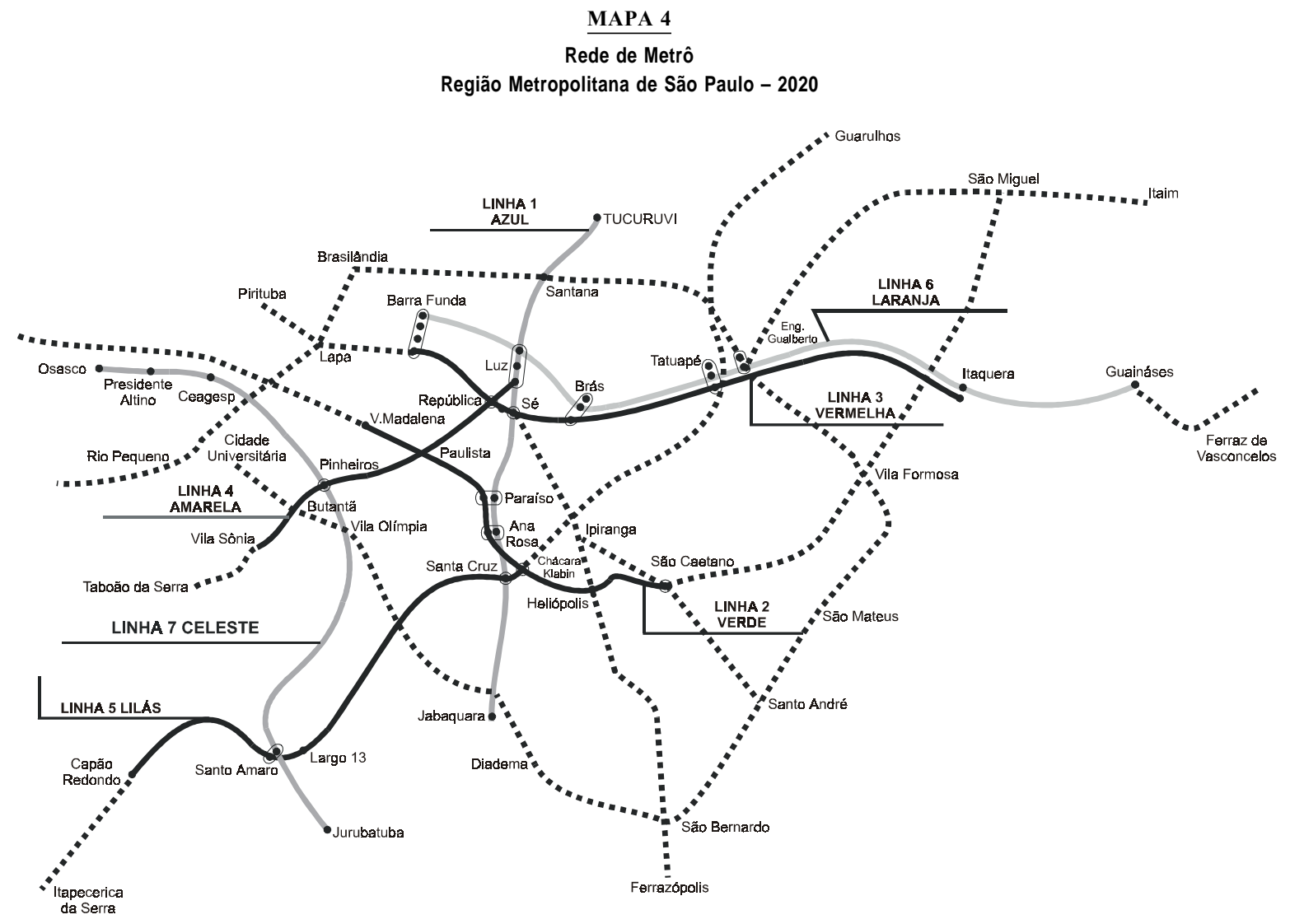

Fonte: Secretaria dos Transportes Metropolitanos (2000). 


\section{QUADRO 1}

Resumo das Proposições do Pitu

Região Metropolitana de São Paulo - 2020

\begin{tabular}{|c|c|c|c|}
\hline Infra-Estrutura & Intervenção & Característica & $\begin{array}{l}\text { Investimento } \\
\text { Total } \\
\text { (R\$ milhões) }\end{array}$ \\
\hline Total & & & 30.312 \\
\hline \multicolumn{4}{|l|}{ Trilhos } \\
\hline Rede metroviária & $\begin{array}{l}\text { Estabelecimento de novas linhas } \\
\text { metroviárias }\end{array}$ & 284 km de metrô & 21.820 \\
\hline Trem especial dos aeroportos & Ligação dos aeroportos urbanos & $44 \mathrm{~km}$ em trem especial & 880 \\
\hline Trem aproximador & Modernização das linhas & $88 \mathrm{~km}$ de melhorias & 440 \\
\hline Trem regional & $\begin{array}{l}\text { Ligação a Campinhas, Sorocaba e } \\
\text { São José dos Campos }\end{array}$ & $177 \mathrm{~km}$ em trem reformulado & 874 \\
\hline \multicolumn{4}{|l|}{ Pneus } \\
\hline Sistema metropolitano & Corredores de ônibus e troncalização & $300 \mathrm{~km}$ de corredores exclusivos & 223 \\
\hline Sistema municipal & $\begin{array}{l}\text { Veículo leve sobre pneus - } \\
\text { VLP e de corredores }\end{array}$ & $260 \mathrm{~km}$ de corredores segregados & 1.596 \\
\hline Sistema complementar & $\begin{array}{l}\text { Linhas circulares de microônibus } \\
\text { no centro expandido }\end{array}$ & 200 km de itinerário em pista simples & 33 \\
\hline \multicolumn{4}{|l|}{ Viário } \\
\hline Plano viário metropolitano & $\begin{array}{l}\text { Novas ligações, maior capacidade, } \\
\text { cruzamentos em desnivel }\end{array}$ & $262 \mathrm{~km}$ de melhorias & 226 \\
\hline Concessão das rodovias & Obras de melhorias nas rodovias & $123 \mathrm{~km}$ de melhorias & 519 \\
\hline Rodoanel & $\begin{array}{l}\text { Construção integral, } \\
\text { complementando o trecho oeste }\end{array}$ & $121 \mathrm{~km}$ em pista dupla & 2.562 \\
\hline $\begin{array}{l}\text { Plano municipal de tráfego } \\
\text { e sistema viário - PMSP }\end{array}$ & $\begin{array}{l}\text { Continuidade das obras } \\
\text { que estão previstas }\end{array}$ & 149 km de melhorias viárias & 283 \\
\hline Incremento operacional do viário - PMSP & Instalação de anéis de tráfego prioritário & $15 \mathrm{~km}$ de melhorias em vias & 527 \\
\hline \multicolumn{4}{|l|}{ Gestão do Trânsito } \\
\hline Pedágio urbano & Introdução no centro expandido & $233 \mathrm{~km}^{2}$ de área com pedágios & 15 \\
\hline Estacionamentos centrais & $\begin{array}{l}\text { Garagens subterrâneas no } \\
\text { centro expandido }\end{array}$ & 30 locais com 11.440 vagas & 223 \\
\hline Estacionamentos periféricos & $\begin{array}{l}\text { Construção de estacionamentos } \\
\text { junto ao sistema de trilhos }\end{array}$ & 40 locais com 26.300 vagas & 91 \\
\hline
\end{tabular}

Fonte: Secretaria dos Transportes Metropolitanos (2000).

nicípios estão revendo prioridades, prazos e isso pode ser incorporado ao Pitu 2020, conforme já explicado, pela flexibilidade de sua metodologia.

\section{Impasse do Investimento Tradicional}

No modo tradicional, previsto o montante de investimento, o Tesouro arcaria com os custos, por meio de recursos diretos da arrecadação ou de empréstimos internos e externos apropriados em seu orçamento. Simplesmente essa era a única forma de financiar o transporte público gerando um impasse cada vez maior, em vista da redução de recursos públicos disponíveis para demandas também maiores em todas as áreas, especialmente na social.

Algumas iniciativas tentaram "quebrar" esse impasse, apropriando, para o planejamento urbano, recursos antes inexistentes no orçamento e criados por planejadores interessados na solução dos problemas da cidade. Apenas como exemplo, citam-se as operações urbanas, mecanismo de obter recursos adicionais pelos benefícios que os construtores urbanos obtêm da proximidade de suas obras da infra-estrutura urbana já consolidada, como transporte coletivo (no caso, o metrô é considerado "benefício"), redes de água, luz, viário, telecomunicações, etc.

Recentemente, busca-se, na iniciativa privada, a parceria para o financiamento. Nos transportes públicos, especialmente no transporte sobre trilhos, essas parcerias estão sendo tentadas na construção da linha 4 - Amarela do metrô, uma engenharia financeira que o Metrô de São Paulo vem montando com as agências internas e externas de financiamento.

São tentativas que, em alguns casos, foram bem-sucedidas. Mas permanece, na base, o uso predominante dos 
recursos públicos que continuam escassos e têm de ser compartilhados com vários outros setores.

Opções a Serem Trabalhadas - Uma opção que vem sendo estudada para o financiamento dos transportes é a vinculação, pela Lei Orçamentária de recursos públicos oriundos do uso da infra-estrutura de transportes, no caso, dos recursos arrecadados com o Imposto sobre a Propriedade de Veículos Automotores - IPVA na região. Esse imposto é, em sua essência, similar a um Imposto de Renda, pois onera quem tem bens, e quanto mais caros os bens, mais imposto se paga. Trata-se, pois, de tornar público que o recurso arrecadado pelo bem que mais onera o sistema viário e a circulação urbana será usado para... a circulação urbana. Além disso, a arrecadação desse imposto pode ser "regionalizada". Do total arrecadado no Estado de São Paulo, $61 \%$ é oriundo do Município de São Paulo, 12\% do restante da Região Metropolitana de São Paulo e 27\%, do restante do Estado de São Paulo. Isto significa que 73\% do recurso é arrecadado nessa metrópole e poderia, em tese, ser destinado a essa região.

Não se trata de vinculação de receita, proibida constitucionalmente, mas uma vinculação contábil pública, para demonstrar, aos pagadores de impostos, que o valor arrecadado com o IPVA é o mesmo aplicado nos investimentos com o transporte público e a acessibilidade. O plano é visível e pode ser cobrado. O imposto é pago e sua "aplicação" pode ser "visualizada". De qualquer forma, essa destinação já existe da parte do Estado, uma vez que os investimentos em transporte nesta gestão, para a Região Metropolitana de São Paulo, equivalem a mais do que a arrecadação de IPVA na região.

Esses são exercícios que um plano que parte da visão da metrópole do futuro e da determinação de resolver os problemas do transporte urbano na Região Metropolitana de São Paulo incentiva. Pois o plano instiga atitudes políticas com "P" maiúsculo, que buscam o entendimento entre os decisores, sejam eles do governo municipal, estadual ou federal, e o entendimento político para a solução definitiva dos problemas, em vez de soluções de uma só gestão. O mérito de um plano como o Pitu 2020 é servir como referência para o futuro. É oferecer um leque de possibilidades suficientemente amplo e abrangente que, em vez de restringir opções, estimule sua constante adaptação e expansão.

\section{REFERÊNCIAS BIBLIOGRÁFICAS}

PREFEITURA DO MUNICÍPIO DE SÃO PAULO. Estudo econômico-financeiro e pré-projeto de engenharia da rede de metrô de São Paulo. São Paulo, 1968.

SÃO PAULO (Estado). Secretaria dos Transportes Metropolitanos. Plano Integrado dos Transportes Urbanos para 2020 - Pitu 2020. São Paulo, 2000. 